\title{
How Do Electoral Incentives Affect Legislator Behavior? Evidence from U.S. State Legislatures
}

\author{
ALEXANDER FOUIRNAIES University of Chicago, United States \\ ANDREW B. HALL Stanford University, United States
}

\begin{abstract}
$A$ classic question about democratic elections is how much they are able to influence politician behavior by forcing them to anticipate future reelection attempts, especially in contexts where voters are not paying close attention and are not well informed. We compile a new dataset containing roughly 780,000 bills, combined with more than 16 million roll-call voting records for roughly 6,000 legislators serving in U.S. state legislatures with term limits. Using an individual-level difference-indifferences design, we find that legislators who can no longer seek reelection sponsor fewer bills, are less productive on committees, and are absent for more floor votes, on average. Building a new dataset of rollcall votes and interest-group ratings, we find little evidence that legislators who cannot run for reelection systematically shift their ideological platforms. In sum, elections appear to influence how legislators allocate their effort in important ways even in low-salience environments but may have less influence on ideological positioning.
\end{abstract}

\section{INTRODUCTION}

$\mathbf{O}$ ne of the oldest questions about democratic elections concerns the extent to which they are able to influence politician behavior by forcing them to anticipate future reelection bids while they are in office. This idea underlies models of electoral accountability (e.g., Ashworth 2005; Banks and Sundaram 1998; Barro 1973; Besley 2006; Fearon 1999; Kartik and Van Weelden 2019), but long-running claims that voters are inattentive or uninformed (e.g., Campbell et al. 1960) have offered plausible reasons to question the power of electoral incentives in many settings. Despite the fundamental nature of this question, it is difficult to obtain direct empirical evidence on how large the effect of electoral incentives on the behavior of elected officials is because doing so requires comparing politician behavior with or without reelection prospects while holding all else equal. A small number of important studies have used term limits as a tool to get at the effects of electoral incentives by comparing incumbents who are allowed to run for reelection to incumbents who are termed out and thus face lower electoral incentives (Alt, Bueno de Mesquita, and Rose 2011; Besley and Case 1995; Ferraz and Finan 2011; List and Sturm 2006). ${ }^{1}$ While these

Alexander Fouirnaies (D), Assistant Professor, Harris School, University of Chicago, United States, fouirnaies@uchicago.edu. Andrew B. Hall (D), Professor, Department of Political Science, and Senior Fellow, Stanford Institute for Economic Policy Research, Stanford University, United States, andrewbhall@stanford.edu.

Received: January 08, 2021; revised: June 19, 2021; accepted: August 13, 2021. First published online: September 27, 2021.

\footnotetext{
${ }^{1}$ A closely related literature studies the effects of term limits on aggregate legislative outcomes. In an especially relevant recent paper, Motolinia (2021) documents how the removal of term limits and the resulting creation of electoral incentives changed the
}

studies are foundational, as we will explain in more detail below, data limitations prevent them from fully separating the effect of electoral incentives from selection effects related to the fact that individuals who win enough elections to hit their binding term limit may be different from those who do not in ways that affect their behavior in office irrespective of electoral incentives.

To overcome this central issue, we collect a new dataset containing over 780,000 bills introduced over the past 30 years in U.S. state legislatures with term limits of three terms or greater. These new data allow us to implement a within-individual difference-in-differences design, comparing the final-term behavior of termed-out legislators to their own behavior in previous terms, relative to counterfactual trends among other legislators in the same legislature. By using this individual-level within-legislature design, we hold fixed any time-invariant attributes of individual legislators and of states, thereby addressing the key selection issues facing existing studies that use term-limits designs. $^{2}$

\footnotetext{
legislative focus of legislatures in Mexico. In a similar vein, Olson and Rogowski (2020) documents how state legislative term limits in the United States increased legislative polarization. These papers suggest ways in which electoral incentives alter the business that legislatures conduct and are complementary to our focus, which is on how electoral incentives influence the behavior of individual legislators as in models of electoral accountability.

${ }^{2}$ Related empirical work studies electoral incentives by comparing incumbent behavior close to election time with behavior farther away from election time (e.g., Huber and Gordon 2004), or by comparing the behavior of officials who face election to other similar officials who are instead appointed (Lim, Snyder, and Strömberg 2015). For a more in depth review, see Ashworth (2012). A recent paper also estimates a dynamic game to, among other things, study the welfare effects of gubernatorial term limits (Sieg and Yoon 2017). Our paper is also similar in spirit to Spenkuch, Montagnes, and Magleby (2018), which studies the manner in which senators cast roll-call votes in anticipation of final-period behavior.
} 
We combine these data with information on a range of publicly observed measures of legislator effortincluding bills sponsored, committee service, and attending roll-call votes - for roughly 6,200 legislators, as well as data on over 16 million roll-call votes cast in these legislatures and more than 80,000 interest-group ratings of legislators, which we use to estimate their ideological positions. The resulting dataset allows us to observe fine-grained measures of how incumbents allocate their effort-covering the full range of variables Dal Bó and Rossi (2011) propose as measures of legislator effort-as well as their ideological positioning.

Studying this new dataset, we document substantial effects of electoral incentives on how legislators allocate their effort. When incumbent state legislators can no longer seek reelection, they sponsor fewer bills, perform less committee service, and are present for fewer votes in the legislature, on average. We experiment with a number of different difference-in-differences designs that build counterfactual trends from other legislators in termed-out states, from legislators in termed-out states prior to the implementation of term limits, and from legislators in other states that do not have term limits, finding consistent evidence for these effects of electoral incentives. The results are broadly consistent with models of electoral accountability and suggest that electoral incentives play an important role in structuring how legislators allocate their effort even in a low-salience setting.

In contrast, we find no evidence that electoral incentives cause legislators to change their ideological positions. Legislators who can no longer seek reelection do not seem to become systematically more extreme or more moderate in their roll-call voting. Examining a number of specific issues where we have access to interest-group ratings of state legislators, we see no obvious patterns of legislators becoming more extreme or more moderate when they can no longer seek reelection. This may be at odds with a long-running literature stemming from Downs (1957) and others that relates electoral incentives to candidate moderation (e.g., Ansolabehere, Snyder, and Stewart 2001; Fiorina 1973; Griffin 2006), mostly in the context of higher salience congressional races, but it is consistent with a view of American state legislative elections in which voters are insufficiently informed about candidate positions to induce them to adopt popular platforms (e.g., Rogers 2017). Alternatively, it is also consistent with "citizen-candidate" models in which candidates have fixed ideological positions that do not vary based on electoral incentives (Alesina 1988; Besley and Coate 1997; Osborne and Slivinski 1996) and with a related set of empirical work exploring the rigidity of candidate positions in American elections (e.g., Hall 2018; Lee, Moretti, and Butler 2004; Poole and Rosenthal 2000)

Whether these patterns are good or bad for democratic representation is unclear, but they suggest the important powers and limitations that elections can have. Elections in state legislatures appear to be an important tool for altering the way that legislators allocate their effort-in contrast with the view that elections in low-salience environments leave legislators free to act unconstrained-but may have less influence over their ideological positions.

\section{USING STATE LEGISLATURES AS A LABORATORY}

Before moving to our data and analysis, in this section, we motivate our focus on term-limited state legislatures, explaining why they are valuable to study both substantively and methodologically.

\section{Term-Limited State Legislatures: An Important Context}

Studying electoral incentives in term-limited state legislatures is substantively valuable for two main reasons.

First, the term-limited legislatures are themselves highly consequential electoral contexts, so understanding how electoral incentives operate in term-limited state legislatures is a directly important question. In the United States, state legislatures are responsible for a broad range of important policies, which means that the behavior of state legislators is important to understand. According to the Urban Institute, in 2015 state governments spent 1.3 trillion dollars and oversaw local governments that spent an additional 1.5 trillion dollars. ${ }^{3}$ The 14 term-limited state legislatures we focus on in this study include the state with the largest economy and most state revenues per capita, California, as well as the state with the fourth largest revenues per capita, Florida. ${ }^{4}$ Recognizing the importance of these legislatures, the debate over implementing state legislative term limits was well-funded and hard fought and has spawned an extremely deep academic literature seeking to understand the effects of term limits in state legislatures (see for example Cain and Kousser 2004; Kousser 2005; Moncrief, Powell, and Storey 2007; Mooney 2009).

Studying electoral incentives in state legislatures complements existing state legislative election research in valuable ways. Existing research suggests that the association between candidate moderation and electoral performance is weaker in state legislative elections than in federal elections (Caughey and Warshaw 2020; Rogers 2017), perhaps because voters are focused on national issues and campaigns (Rogers 2016). Consistent with this, Kroeger (2017) documents high rates of interest group influence in the legislative process, especially for term-limited legislators. ${ }^{5}$ De Benedictis-Kessner

\footnotetext{
${ }^{3}$ Roughly $22 \%$ of this money was spent on elementary and secondary education; $21 \%$ was spent on public welfare programs; the remainder largely went to higher education, health and hospitals, police, and infrastructure. See https://www.urban.org/policy-centers/cross-cen ter-initiatives/state-local-finance-initiative/projects/state-and-localbackgrounders/state-and-local-expenditures.

${ }^{4}$ See https://www.taxpolicycenter.org/statistics/rankings-state-andlocal-capita-general-revenue.

5 This paper, and our focus on state legislative term limits, connects to a very extensive literature on the effects of state legislative term limits on important political outcomes including interest group influence,
} 
and Warshaw (2020) find a link between local economic performance and punishment or reward for state legislators of the president's party, further evidence potentially consistent with voter inattention to state legislators' own actions and behavior. Summing up the state of affairs, Rogers (2017, abstract) writes that "while state legislators wield considerable policymaking power, elections do not appear to hold many legislators accountable for their lawmaking." We complement this valuable body of work by looking specifically for a different type of accountability defined in formal models of electoral accountability: the actions legislators take in the legislature in response to electoral pressures, distinct from the literature's primary current focus on election outcomes. Even if election outcomes are not a function of legislators' ideological positioning or their personal efforts to affect the economy, the threat of reelection could still change the actions and efforts of politicians while they are in office.

Second, studying term-limited state legislatures teaches us something about the mechanics of democracy that is likely to generalize to other electoral contexts. As Mooney (2009) shows, term-limited state legislatures are similar, on average, to other state legislatures on a wide variety of relevant attributes, suggesting that effects estimated in term-limited state legislatures may generalize quite readily to other state legislatures, and state legislatures are thought to be a useful laboratory we can use to understand the workings of electoral politics more generally. There is a long-running and rapidly growing literature that sheds light on foundational theories of electoral politics by using state legislatures as a test bed, studying core topics like how money influences electoral politics (e.g., Barber 2015; Harvey and Mattia Forthcoming), the role of gender bias in legislative politics (e.g., Kathlene 1994; Sanbonmatsu 2002), race and representation (e.g., Butler and Broockman 2011; Grumbach and Sahn 2020), and legislative polarization (e.g., Olson and Rogowski 2020; Shor and McCarty 2011). ${ }^{6}$ The state legislatures provide a particularly valuable test bed for questions about electoral accountability because, like so many elections across the world, they are relatively low salience and feature low levels of voter information; as a result, they provide a hard test for models of electoral accountability.

\section{New Design for Differencing Out Unobserved Politician Type}

In addition to their substantive import, studying the U.S. state legislatures also makes it possible to use a different and potentially more robust design than previous term-limits papers. A simple model of electoral

the balance of power between the legislature and the executive, the diversity of the legislature, and the advantage of incumbents. For brevity's sake, we will not catalogue this work here, but a helpful review can be found in Mooney (2009).

${ }^{6}$ This is a tiny sampling of the very large literature studying state legislatures; it is intended to be purely illustrative and not exhaustive. accountability with both moral hazard and adverse selection predicts that politicians who survive until their binding term limit will be on average of higher quality than those who do not, and this is the key empirical challenge that the term-limits literature must solve (Alt, Bueno de Mesquita, and Rose 2011). ${ }^{7}$ Besley and Case (1995) and List and Sturm (2006) employ difference-in-differences designs that leverage withinstate variation in whether the sitting governor is a lame duck. As Alt, Bueno de Mesquita, and Rose (2011) explain, though, because lame-duck governors may be of higher average quality than governors who do not make it to their lame-duck term, the resulting estimates of electoral incentives may be downwardly biased. Although the true effect of the removal of electoral incentives on incumbent effort might be large and negative, there may be an offsetting, positive difference between lame ducks and nonlame ducks reflecting the higher competence of governors who make it to their final term.

Alt, Bueno de Mesquita, and Rose (2011) address this issue of selection by focusing on states that switch from having a one-term limit for governors to having a two-term limit. The paper compares outcomes for firstterm lame ducks with outcomes for first-term governors in the same state later in time, who are eligible for reelection because the state expanded its term limit - as both groups have won exactly one election at this point, they should be of similar underlying quality while facing different electoral incentives. While an important improvement, this approach requires assuming that the underlying type distribution of first-term governors is the same before and after the term limit is extended from one term to two. If higher-quality people run for office when there is an opportunity to serve two terms instead of one, the Alt, Bueno de Mesquita, and Rose (2011) design will overestimate the effect of electoral incentives.

Ferraz and Finan (2011) address the selection issue another way, by comparing mayors in a two-term term limit setting who barely won election into a second term, thus becoming lame ducks, with mayors who barely won election into their first term. Because mayors barely elected into their second term have survived one more election cycle than mayors barely elected into their first term and thus may be of higher type on average, the paper restricts focus among the barewinning first-term mayors to those who go on to win a second term. However, this set of first-term incumbents could be different from those serving in a second term; they barely won a first election, but went on to win a second election by any margin, whereas the lame-duck sample won their first election by any margin but barely won their reelection. Depending on the relationship between underlying types for corruption (the outcome in the paper) and electoral selection, this could bias the estimate of electoral incentives in either direction.

\footnotetext{
${ }^{7}$ We review the model from Alt, Bueno de Mesquita, and Rose (2011) in the Appendix and explain why our design addresses this issue.
} 
TABLE 1. Summary of Dataset Coverage

\begin{tabular}{lllc}
\hline State & Chambers & Data range & Year when limits took effect \\
\hline AR & house & $2001-2016$ & 1998 \\
AZ & house \& senate & $1991-2016$ & 2000 \\
CA & house & $1999-2016$ & 1996 \\
CO & house & $2003-2016$ & 1998 \\
FL & house & $2003-2016$ & 2000 \\
LA & house & $1996-2015$ & 2007 \\
ME & house \& senate & $2003-2016$ & 1996 \\
MI & house & $2001-2016$ & 1998 \\
MO & house & $1999-2016$ & 2002 \\
MT & house & $2001-2016$ & 2000 \\
NV & house & $1999-2016$ & 2010 \\
OH & house & $2007-2014$ & 2000 \\
OK & house & $1999-2016$ & 2004 \\
SD & house & $2003-2016$ & 2000 \\
\hline
\end{tabular}

Note: The table shows the states and chambers that enter our main analysis, the years for which we have data, and the year in which the term limits took effect.

The fundamental challenge in all these papers is that making cross-person comparisons between politicians who do or do not face a binding term limit risks conflating electoral selection for different types with the effects of electoral incentives. The state legislative context makes it possible to hold individual type fixed by making within-person comparisons to estimate electoral incentives effects. Because the term limits in our sample are longer than two terms and because there are many more state legislators than there are governors, we can use a difference-in-differences design at the individual level, assessing how much an individual changes her effort allocation when she hits her binding term limit, relative to her own behavior prior to the term limit. While this approach has its own challenges, which we discuss below, it is the only termlimits paper to date, to our knowledge, that is able to fully difference out the time-invariant components of individual incumbent type.

\section{DATA ON LEGISLATOR BEHAVIOR IN STATE LEGISLATURES}

To implement our study, we began by collecting primary source data on legislation and roll-call voting in term-limited states, as our study focuses on term limits. ${ }^{8}$ Our design requires that legislators be limited to three terms or more, which excludes Nebraska's unicameral legislature from our analysis. Our design also requires that legislators not serve staggered terms, as this severely complicates the construction of counterfactual trends, so we exclude a number of the state senates in term-limited states. The final dataset covers 14 states and includes the 14 state houses (AR, AZ, CA, CO, FL, ME, MI, MO, MT, NV, OH, OK, SD, and LA) and

\footnotetext{
${ }^{8}$ We gathered information on states' term-limit laws from the National Conference of State Legislatures.
}

2 state senates ( $\mathrm{AZ}$ and $\mathrm{ME}$ ) that meet these conditions.

Table 1 summarizes the term-limited states, chambers, and years that we analyze in our main analysesthose that meet the above conditions and that provided sufficient data to allow us to construct our main measure of legislator productivity, which we will define below. Because different states offer data going back different lengths of time, our panel is unbalanced; for some states, as the table shows, we are able to exploit data from sessions that took place prior to the implementation of term limits. More exact details on the sample, including the number of legislators included in each state-year, are available in the Appendix.

For each term-limited chamber in our sample, we downloaded roll-call voting records and additional information about bills introduced to the legislature from official online sources. Because each state required its own tailored approach-in some cases, the data are relatively well formatted and can be scraped automatically before going through extensive cleaning, but in others the approach must be almost entirely manual - the process was quite time consuming, with each state taking several weeks (roughly 100 hours) of concerted effort, on average. Though in future work we intend to compile a panel of all 99 state legislatures, this is why we focused first only on the states where we could directly study the effect of electoral incentives using term limits. For the purposes of comparing termed-out legislators with legislators in other states without term limits, however, we also did add two non-term-limited states, New York and Texas. We discuss the value of using these two states below in the relevant analysis.

\section{Theoretical Focus on Legislator Productivity}

To understand how electoral incentives affect legislator behavior, we want to focus on important legislative activities that are publicly visible. In the Appendix, 
we review a basic model of electoral accountability from Alt, Bueno de Mesquita, and Rose (2011) that motivates our empirical analysis. In accountability models, voters try to infer whether their legislator is more competent than the average challenger they could elect instead, without being able to observe competence directly. While these models are abstract and suppose that voters draw these inferences based on the "state of the world," it is reasonable to suppose that in the real-world voters also use the way that their legislators allocate their effort to important legislative activities to evaluate them. If electoral incentives are important, we hypothesize, they should induce legislators to allocate more effort to observable forms of effort in order to affect voters' inferences and increase their chance of reelection.

What are these important legislative activities? We focus on three, all drawn from previous literature (Dal Bó and Rossi 2011; Titiunik 2016): the degree to which legislators introduce legislation, work in committees, and show up to vote on roll-call votes. We focus on these three categories because they cover the most important publicly visible efforts that legislators, including American state legislators, can undertake on behalf of their constituents. Sponsoring legislation is the central way that legislators can craft a personal political agenda (e.g., Schiller 1995). Serving on committees provides legislators with opportunities to influence the legislative agenda, push forward viable legislation, and mark up legislation with constituent interests in mind (e.g., Gilligan and Krehbiel 1987; Shepsle 1978). Finally, casting roll-call votes is a prime opportunity for legislators to take visible positions for their constituents (Mayhew 1974), and not being present to cast roll-call votes is one of the most basic forms of legislator shirking (Bender and Lott 1996; Rothenberg and Sanders 2000). While the literature has often thought about missing roll-call votes as pure shirking, legislators may also strategically abstain from casting roll-call votes in some cases (e.g., Shepsle 1972). In such cases, the measure would still reflect the degree to which legislators are allocating their effort toward visible position taking.

Is it reasonable to suppose that, even in a low-salience environment like state legislatures, electoral incentives, if they exist, would affect these actions for individual legislators? While most voters do not pay close attention to their state legislators' behavior, we have several reasons to think that introducing bills, serving on committees, and casting roll-call votes could be important for legislators seeking reelection. First, legislators can advertise these activities to voters. Indeed, legislators themselves prominently feature these activities in their own communications and campaign materials. As part of our research, we often found ourselves on state legislators' personal webpages. It is very common for these webpages to list the legislator's committee service and to boast about bills the legislator has introduced.

Second, while voters themselves may not pay attention to these activities, primary or general-election opponents and interest groups can. Brown and
Goodliffe (2017), for example, offer several examples of state legislative races in which opponents question the attention and effort of an incumbent by pointing to their high absentee rates from roll-call votes. Although many state legislative races are uncontested, incumbents may focus on these visible activities in part to ward off primary or general-election challengers.

Third, and finally, interest groups and parties care a great deal about who serves on which committees and on what happens on these committees (e.g., Fouirnaies and Hall 2018). As a result, a legislator seeking reelection has reasons to participate actively on committees, not only to gain voter support but also to gain support from interest groups and their party, who in turn can foster voter support.

These outcomes are not entirely in the legislator's personal control. Most obviously, legislators do not get to choose what committees they are on unilaterally. If the majority party decides to give fewer committee assignments to a termed-out legislator because they want to burnish the reelection credentials of their more-junior members, this would still be an important effect of electoral incentives, but it should not be interpreted as purely an individual-level effect. It is conceivable that term-limited legislators could also coordinate their bill sponsorship with their party. For these reasons, we should be cautious in interpreting our effects of electoral incentives as partly reflecting systematic strategic considerations of parties; however, we also perform analyses on the separate components of our productivity index, finding consistent effects across those measures with more potential party control (especially the committee index) and those with less (especially the rate of casting roll-call votes). In the Appendix, we also assess whether our results vary across states where party leadership is thought to be stronger versus weaker, finding no evidence that the effects are concentrated in states where parties might influence individual legislator behavior less.

Last, while individual legislators do have personal control over introducing their own bills, some state legislatures limit the number of bills a legislator can introduce. If most legislators regularly hit these limits in these states, measuring the number of bills introduced by a legislator would not provide a lot of information about legislator effort allocation. Fortunately, only half of the term-limited states in our sample have such limits, according to the National Conference of State Legislatures, and not all of the limits are very stringent. ${ }^{9}$ We can also see in our data that individual legislators do not seem to have dramatically truncated levels of bill sponsorship: the average number of bills sponsored in a given year for an individual legislator is 27 , with a standard deviation across legislators of 30 and a within-legislator standard deviation of 17 , indicating that legislators vary substantially in the number of bills they sponsor by year. If the limit on bills introduced were an important constraint for our analysis, the

\footnotetext{
${ }^{9}$ See https://www.ncsl.org/research/about-state-legislatures/limitingbill-introductions.aspx.
} 
within-legislator standard deviation would be close to zero.

For these reasons, we think these are valuable measures of legislator productivity in state legislatures.

\section{Measuring Legislative Productivity}

Having justified the theoretical value of our measures of legislator productivity, we now discuss how we operationalize them with our data.

\section{Sponsoring Legislation}

Based on the formatting of the data from each state in our sample, we create a bill-level dataset containing the bill's sponsor, its name, a brief textual summary of its purpose when available, and whether it passed into law or not. ${ }^{10}$ For our analyses, we collapse this dataset by legislator and term so that we know the total number of bills sponsored by each legislator in each term.

\section{Committee Service}

To study committee service, we start from a dataset on state legislative committee assignments and committee chairmanships that we collected from primary sources for two previous studies (Fouirnaies 2018; Fouirnaies and Hall 2018). We add to this dataset new information on vice committee chair positions for all state legislatures over the study's period, collected manually from the state legislative Yellowbooks.

Using these data, we construct a simple measure of a legislator's committee activities based on her formal responsibilities on the various committees she serves on. We measure legislator $i$ 's responsibilities on committee $j$ in chamber $c$ at time $t$, and we construct the following activity index:

$$
\text { Committee Activity } \text { Ajct }=\left\{\begin{array}{l}
0 \text { if } i \text { is a not a member of } \\
\text { committee } j \text { at time } t \\
1 \text { if } i \text { is an ordinary member } \\
\text { of committee } j \text { at time } t \\
2 \text { if } i \text { is vice chair of } \\
\text { committee } j \text { at time } t \\
3 \text { if } i \text { is chair of } \\
\text { committee } j \text { at time } t .
\end{array}\right.
$$

These values reflect the idea that committee chairs hold more responsibility than vice chairs do and vice chairs hold more responsibility than rank-and-file committee members. The relative weights, ranging from $0-3$, are clearly somewhat arbitrary, but none of the results depend on these weights, as we will show below. To construct an aggregate measure of a legislator's formal

\footnotetext{
${ }^{10}$ Where possible, we also collect more information on legislationincluding the full text of bills and the estimated fiscal consequences of bills-by downloading and converting full pdf files of the legislative journals.
}

responsibilities, we then sum across all committees $J$ in a given chamber and term:

$$
\text { Committee Activity }_{i c t}=\sum_{j_{c t} \in J_{c t}} \text { Committee Activity }_{i j c t} \text {, }
$$

where $J_{c t}$ is the set of committees in chamber $c$ at time $t$.

\section{Roll-Call Voting}

To study how legislators vote on the floor, we collected data on roll-call votes, again from each state's official website. The precise source of these data varies from state to state; in some cases, this information is provided in an easily downloadable format, while in others it is in PDFs that we have converted to text using automated techniques. In total, we have over 16 million individual roll-call votes linked to specific candidates. There is significant variation across states in terms of what roll-call votes they record. Some states only record and publish the final vote taken at the third reading of the bill or at the final passage, whereas other states make every single roll-call vote publicly available. Differences in data availability like these will not affect any of the results presented because all comparisons are made within the same chamber and term.

Using these data, we measure participation in floor votes by calculating the percentage of floor roll-call votes in which legislator $i$ is recorded a voting either in favor or against the motion.

\section{Aggregate Productivity Index}

In order to focus the analysis on a single primary quantity that captures all of these relevant dimensions of effort, we follow Dal Bó and Rossi (2011) and use principal components analysis to construct a productivity index by extracting the latent dimension underlying the three measures of productivity discussed above. For ease of interpretation, we normalize this index to mean zero and unit standard deviation.

We combine these measures with data on all state legislature elections for the period of the study, which we obtain from Klarner et al. (2013), as cleaned and organized in Fouirnaies and Hall (2018). We use the election data to track each legislator's terms of service so that we know when they are being termed out of their legislative chambers. Table A.1 shows the specific states and year ranges for the final dataset on termlimited state legislatures.

States vary in which components of the productivity index they make publicly available. Our main analyses focus on the subset of cases for which we observe all three components; however, we also present results for each component separately that do not condition on the availability of the other components.

\section{Measuring Legislator Ideology}

As we explained in the introduction, we are also interested in understanding whether legislators change their 
FIGURE 1. Reelection Incentives and Legislator Productivity

(a) Three-Term Term Limits

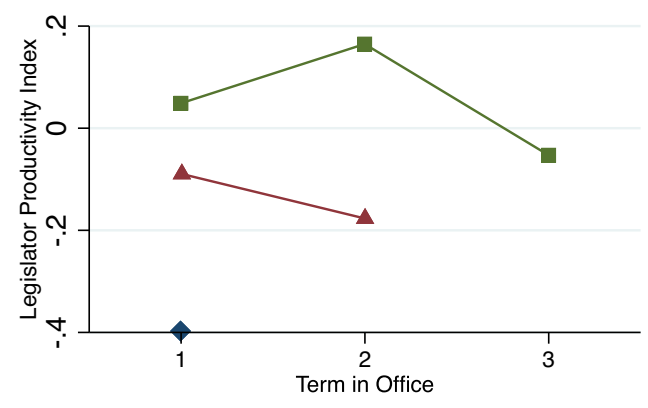

(b) Four-Term Term Limits

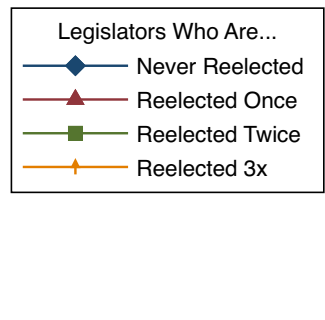

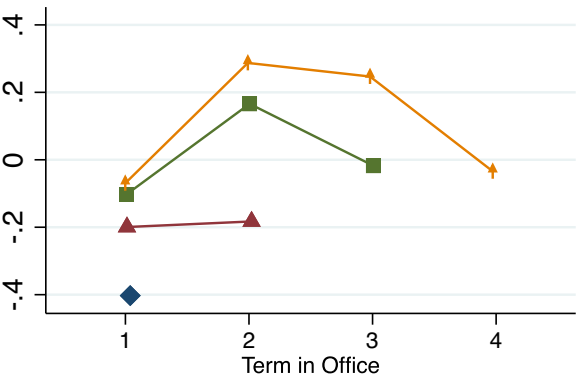

Note: Term-limited legislators are less productive in their final terms, on average.

ideological platforms in response to electoral incentives. To study this question, we use the roll-call votes to scale incumbents ideologically, using the popular WNOMINATE algorithm (Carroll et al. 2009; Poole and Rosenthal 1985). The algorithm works by applying a model of discrete choice to extract meaningful dimensions of variation from the roll-call voting matrix (where legislators are rows and bills are columns, or vice-versa.) We use the wnominate package in $\mathrm{R}$ to implement the scaling, and we extract the first dimension of the score as our measure of ideological positioning. The W-NOMINATE scalings are not immediately comparable over time, as they are estimated separately for each chamber term; however, by using them in a difference-in-differences design, we can compare incumbents' relative positioning within their chamber over time. The scalings run from negative (for more liberal) to positive (for more conservative); we take the absolute value of the scaling to indicate a legislator's extremity, following previous work (e.g., Canes-Wrone, Brady, and Cogan 2002).

It is possible that W-NOMINATE is too coarse to detect important issue-specific shifts in positions for term-limited legislators. To complement this aggregate analysis, we also gathered information on interestgroup ratings of legislators in seven important issue areas: abortion, business, education, environment, guns, taxes, and labor unions. The interest-group ratings either come from the nonprofit organization Project Vote Smart or directly from the website of an interest group. To construct a rating for a legislator, most of these groups select a set of bills that are important to their agenda in a particular session and then for each legislator calculate for the percentage of votes in which the legislator's vote is aligned with the position of the interest group. We rely on the classification of issue areas produced by Project Vote Smart so that we can estimate effects separately for each issue. We focus on seven issue areas for which a substantial number of legislators receive ratings, and we collapse the remaining issue areas into a miscellaneous "other" category. We link each legislator in our dataset to the scores produced by the different interest groups. In the Appendix, we provide additional information on the specific interest groups, their main issue area, and the range of years and states for which we have ratings.

\section{ELECTORAL INCENTIVES INCREASE LEGISLATOR PRODUCTIVITY}

In this section, we use our data on state legislatures to test whether electoral incentives induce state legislators to allocate more of their effort toward visible measures of legislative productivity.

\section{Graphical Evidence}

We begin with a graphical analysis. Figure 1 displays legislator productivity for legislators who serve different numbers of terms in office. In the left panel, we study states with three-term term limits, and we compare productivity across terms in office for three sets of legislators: those who only serve one term in office, those who serve two terms in office, and those who serve three terms in office and are then termed out of the legislature.

The figure suggests that legislators are less productive in their final term than in their previous terms. ${ }^{11}$ Patterns are extremely similar in the right panel when we study states with four-term term limits. While suggestive, these graphical patterns do not account for the main issues of causal inference we discussed earlier in the paper; accordingly, we turn now to formal estimates that address these issues.

\section{Formal Estimates of the Effect of Reelection Incentives}

The main empirical challenge to using term limits to study reelection incentives is the need to separate incentives from selection. We improve on the designs

\footnotetext{
${ }^{11}$ The figure also shows that legislators who survive until their third term are, on average, more productive than legislators who do not survive until their third term. We will return to these "selection effects" in the final part of the paper.
} 
in the existing empirical literature by implementing a within-individual, within-state difference-in-differences design. This design separates the accountability effect from time-invariant competence effects and linear learning effects that would otherwise bias the estimates.

Specifically, we use OLS to estimate equations of the form

$$
\text { Productivity }_{i c t}=\beta_{a} \text { Term Limited }_{i c t}+\alpha_{i}+\delta_{c t}+\varepsilon_{i c t} \text {, }
$$

where Productivity $_{i c t}$ is a measure of productivity for legislator $i$ in chamber $c$ at time $t$. The variable TermLimited $_{i c t}$ is an indicator for whether legislator $i$ at time $t$ is serving her final term before the binding term limit kicks in. Finally, $\alpha_{i}$ stands in for individual fixed effects, and $\delta_{c t}$ stands in for chamber-by-term fixed effects. This difference-in-differences design makes within-incumbent comparisons of the change in productivity for legislators who face a binding term limits versus those who do not. In the Appendix, we show that $\beta_{a}$ is an estimate of the electoral incentives effect as defined in the model from Alt, Bueno de Mesquita, and Rose (2011).

\section{Main Results}

Table 2 presents the overall estimates of being term limited on legislative productivity. In the first column, we use legislator and chamber-year fixed effects so that we are comparing the change in productivity for termed-out legislators with changes for legislators who are in the same legislature at the same time but who are not yet termed-out themselves. We see a noticeable on-average decrease in productivity for legislators when they can no longer seek reelection. The estimates indicate a decrease of roughly one quarter of a standard deviation in the distribution of legislator productivity, reflecting substantively meaningful shifts in all three underlying components of the productivity index, which we will estimate directly below.

In the second column, we use chamber-party-year fixed effects to ensure that the results are not driven by differential trends across parties within each legislature - this could be important, if productivity is in large part a function of majority-party status. However, as we see, the estimate is unchanged in this specification.

In sum, these estimates indicate that termed-out legislators respond to the reduction in their electoral incentives by allocating less effort to visible dimensions of effort, as predicted by models of electoral accountability, even despite the low salience and low information levels in state legislative elections. ${ }^{12}$

In a normal difference-in-differences framework, we would validate these results by including leads of the treatment variable to look for evidence of pretrending. Because of the unusual nature of our design, where the

\footnotetext{
${ }^{12}$ As we discuss in the Appendix, these models also predict that elections will systematically select for legislators who are more productive. In the Appendix, we evaluate this prediction, finding consistent evidence that more-productive legislators perform better, electorally, on average.
}

\section{TABLE 2. Effect of Electoral Incentives on Legislator Productivity}

\begin{tabular}{lcc}
\hline & \multicolumn{2}{c}{$\begin{array}{c}\text { Legislative } \\
\text { productivity index }\end{array}$} \\
\cline { 2 - 3 } & $(1)$ & $(2)$ \\
\hline Term limited & -0.24 & -0.24 \\
& $(0.03)$ & $(0.03)$ \\
\hline$N$ & 11,109 & 11,109 \\
Legislators & 4,642 & 4,642 \\
Outcome mean & 0.00 & 0.00 \\
Standard dev. & 1.00 & 1.00 \\
Legislator FE & Yes & Yes \\
Chamber-year FE & Yes & \\
Chamber-party-year FE & & Yes \\
\hline $\begin{array}{l}\text { Note: In their final term, term-limited legislators are less product- } \\
\text { ive. In all columns, the outcome variable is the first principal } \\
\text { component from a PCA of the three measures of effort. The unit } \\
\text { of observation is a legislator. The variable Term limited is a } \\
\text { dummy variable indicating whether a legislator is in her final, } \\
\text { term-limited term. Robust standard errors clustered by legislator } \\
\text { in parentheses. }\end{array}$ \\
\hline
\end{tabular}

number of periods is fixed at a small number for treated legislators, we cannot perform these typical diagnostics. Instead, we now turn to validating the design by exploring the robustness of the estimates to a variety of alternative approaches.

\section{Robustness of Main Results}

The estimates in Table 2 suggest that electoral incentives importantly affect legislator productivity because they indicate a noticeable decrease in productivity for legislators who can no longer seek reelection. These estimates, which are our preferred estimates, make comparisons only within a particular term-limited legislature at a specific point, which means that the "control group" from which counterfactual trends are constructed are all legislators who themselves are serving in legislatures with term limits.

This is valuable because different states have very different legislative processes, which makes it likely that each state will experience its own idiosyncratic shocks to legislative productivity. However, it also raises two potential issues with parallel trends.

First, these control legislators must be of lower seniority than are the termed-out legislators with which they are being compared because they all serve in the same legislature with the same term-limit rules. This means we are extrapolating from changes in productivity for someone with fewer terms of seniority to obtain a counterfactual for termed-out legislators. If the relationship between productivity and terms of service is nonlinear - for example, if productivity grows fast in early terms as legislators learn about the legislature but then levels off once they've gained sufficient experience - then the estimates above would be overestimates of the effect of electoral incentives because 
TABLE 3. Robustness to Alternative Specifications

\begin{tabular}{|c|c|c|c|c|}
\hline & \multicolumn{4}{|c|}{ Legislative productivity index } \\
\hline & (1) & $(2)$ & (3) & (4) \\
\hline Term limited & $\begin{array}{l}-0.23 \\
(0.03)\end{array}$ & $\begin{array}{l}-0.09 \\
(0.03)\end{array}$ & $\begin{array}{l}-0.09 \\
(0.03)\end{array}$ & $\begin{array}{l}-0.41 \\
(0.03)\end{array}$ \\
\hline$N$ & 11,109 & 11,109 & 11,109 & 11,416 \\
\hline Legislators & 4,642 & 4,642 & 4,642 & 1,506 \\
\hline Outcome mean & 0.00 & 0.00 & 0.00 & 0.00 \\
\hline Standard dev. & 1.00 & 1.00 & 1.00 & 1.00 \\
\hline Legislator FE & Yes & Yes & Yes & Yes \\
\hline Chamber-year FE & Yes & & & \\
\hline Year FE & & Yes & & \\
\hline Log(seniority) & Yes & & & \\
\hline Seniority FE & & Yes & & \\
\hline Cohort-year FE & & & Yes & \\
\hline Matched to NY/TX legs & & & & Yes \\
\hline Match pair-year FEs & & & & Yes \\
\hline
\end{tabular}

the large increases in productivity for less-senior legislators would be used as the counterfactual for termed-out legislators who, because they are more senior, would not actually see such large productivity increases even if they weren't termed out in their more advanced terms.

In Table 3, we use a number of specifications to address this potential issue, continuing to find consistent decreases in productivity for term-limited legislators.

In the first column, we add a control for the log of the number of terms a legislator has served in the legislature to try to address the possibility of concave learning across terms in a parametric manner. In this specification, we continue to make comparisons only within legislatures, but at the cost of having to impose a particular parametric specification. As the table shows, we continue to find a negative effect of being term limited on productivity.

The next two columns avoid imposing a parametric specification, but at the cost of using cross-legislature information. In the second column, we control for seniority more flexibly by including seniority fixed effects, but we switch from chamber-year to year fixed effects, as there is insufficient variation within termlimited states to estimate both chamber-year fixed effects and seniority fixed effects simultaneously. In the third column, we use cohort-year fixed effects instead of chamber-year fixed effects. This means that we are constructing counterfactual trends using legislators in any state in our sample who entered the legislature in the same year as a given treated legislator. Because different states in our sample have different term-limit lengths and also implemented their term limits at different times, this allows us to get counterfactual trends while holding experience constant, avoiding the need to compare across levels of seniority, thus neutralizing basic learning effects. In both of these specifications, while the estimate shrinks somewhat in size, it remains negative and statistically significant.

The second potential issue is that legislators in termlimited legislatures may be anticipating their own future final terms. Knowing that they are going to be termed-out themselves if they win enough of their reelection bids could affect their effort allocation in their early terms, in which case they do not provide a good counterfactual for how termed-out legislators would behave if they could still run for reelection.

The final column of the table addresses anticipatory effects as well as the issue of making comparisons across legislators of different levels of seniority by bringing in data from two non-term-limited states, New York and Texas. ${ }^{13}$ Ideally we would have data from all non-term-limited states, but as we explained earlier, it is not tractable to collect these data universally. New York and Texas are good comparison states without term limits because electoral incentives for legislators in these states should be broadly representative of the kinds of incentives at play in our sample. As we show in Figures A.3 and A.4, New York and Texas vary in their level of legislative professionalism

\footnotetext{
${ }^{13}$ This analysis also addresses a third concern related to mean reversion. In our baseline specification, candidates who survive to their final term may have been particularly "lucky" in past sessions in the legislature. By conditioning on their survival to their third term, while not conditioning on survival in the control group, mean reversion could explain some of the on-average decrease in productivity we observe in the treated group. We have tested for this in our baseline model by including an indicator for a legislator's final term (whether because of term limits or not), and the main estimate shrinks but remains large and negative. Using states without term limits provides a superior way to address mean reversion, though, because we can use control legislators who have survived the same number of electoral terms.
} 
TABLE 4. Effect of Electoral Incentives on Attendance, Bill Sponsorship, and Committee Activity

\begin{tabular}{|c|c|c|c|c|c|c|}
\hline & \multicolumn{2}{|c|}{ Percentage of floor votes } & \multicolumn{2}{|c|}{ Sponsored bills } & \multicolumn{2}{|c|}{ Committee activity } \\
\hline & (1) & (2) & (3) & (4) & (5) & (6) \\
\hline Term limited & $\begin{array}{c}-2.70 \\
(0.53)\end{array}$ & $\begin{array}{c}-2.63 \\
(0.53)\end{array}$ & $\begin{array}{c}-1.63 \\
(0.77)\end{array}$ & $\begin{array}{c}-1.34 \\
(0.70)\end{array}$ & $\begin{array}{c}-0.31 \\
(0.06)\end{array}$ & $\begin{array}{c}-0.30 \\
(0.05)\end{array}$ \\
\hline$N$ & 11,109 & 11,109 & 16,727 & 16,727 & 16,255 & 16,255 \\
\hline Legislators & 4,642 & 4,642 & 6,207 & 6,207 & 6,123 & 6,123 \\
\hline Outcome mean & 90.48 & 90.48 & 27.32 & 27.32 & 3.84 & 3.84 \\
\hline Standard dev. & 16.25 & 16.25 & 35.17 & 35.17 & 2.32 & 2.32 \\
\hline Legislator FE & Yes & Yes & Yes & Yes & Yes & Yes \\
\hline Chamber-year FE & Yes & & Yes & & Yes & \\
\hline Chamber-party-year FE & & Yes & & Yes & & Yes \\
\hline
\end{tabular}

and in how much they pay their legislators in ways that helpfully span the range of the term-limited legislatures. New York is a highly professionalized legislature with high legislative salaries, and is quite similar to California, the largest term-limited state in our sample. Texas is much less professionalized and pays legislators much less, which places it roughly in the middle of the other term-limited states in our sample. While other states might also serve as useful control cases, New York and Texas are particularly emblematic cases that also offered data that were relatively straightforward to digitize, so we focus on them.

Using these non-term-limited states allows us to compare term-limited legislators with legislators in other states who have served the same number of terms but who are not facing term limits and therefore not structuring their behavior in anticipation of them.

For each observation for treated legislator $i$ in year $t$ - that is, for each observation for a legislator who goes on to hit a binding term limit - we create a matched control "synthetic" legislator whose productivity is the average productivity for legislators in New York and Texas in year $t$ who have served the same number of terms in the legislature as legislator $i$. We then estimate the difference-in-differences design using legislator fixed effects and match-pair-year fixed effects so that we are comparing the change in productivity for a term-limited legislator in their final term with the corresponding change in productivity for legislators in New York and Texas.

As the table shows, in this specification, which addresses both the learning issue and the anticipatory issue, we actually find a much larger and just as precise estimate.

While the estimates vary in magnitude across these robustness checks, they are consistently negative and statistically significant. Keeping this in mind, we now turn back to our preferred specification in order to discuss the substantive interpretation of these estimates on the productivity index.

\section{Understanding Effects on Productivity}

The analyses above presented and validated our difference-in-differences design estimates that indicate a consistent negative effect of being term limited on legislator productivity. We focus on the productivity index because it captures the most information about a legislator's behavior; however, it is difficult to interpret on its own. In this section, we use our main specifications from above, focusing only on within-state information, to estimate effects on each of the three components of the productivity index in order to assess what these productivity effects mean.

Table 4 presents the resulting estimates. The first two columns show the estimated effect of being term limited on showing up to cast roll-call votes. In their final term, the rate at which termed-out legislators cast votes on roll calls decreases by approximately 2.7 percentage points, from an overall mean of roughly $90 \%$. Inverting this, control legislators miss roughly $10 \%$ of votes, and treated legislators miss roughly $12.7 \%$ of votes - a proportional increase in abstention of $27 \%$. Interestingly, this 2.7-percentage-point effect is meaningfully larger than the estimated effect of term length on abstention reported in Titiunik (2016), which was roughly 1.8 to 2.1 percentage points across contexts.

Columns 3 and 4 show estimates on the number of bills sponsored. While we take the log of this variable in constructing the productivity index, we show the results here in levels for interpretability (estimates are substantively similar in $\log$ ). In their final term, termedout legislators introduce roughly 1.6 fewer bills (column 3 ) or 1.3 fewer bills (column 4) compared with an overall mean of 27 bills. This is roughly a $6 \%$ decline in proportional terms.

Finally, columns 5 and 6 show that, in their final term, termed-out legislators' committee activity index declines by roughly 0.3 points from an overall mean of 3.8 - roughly an $8 \%$ decline in proportional terms. 
Taken together, these estimates on the components of the productivity index suggest that the removal of electoral incentives leads to meaningful shifts in legislator behavior across all three components.

\section{Variation in the Estimate Supports Its Validity}

In the Appendix Table A.3, we explore several primary sources of heterogeneity in the overall effect of being term limited on legislator productivity that further support the logic of our finding. In particular, we show that the effect of being term limited is substantially larger for states where the term limit is a lifetime limit, meaning that the legislator can never again run for her current office, as compared with states where the term limit is merely "consecutive," which means the termedout legislator only has to sit out a term before running again. Because the lifetime limits weaken electoral incentives more dramatically, it is reassuring to see that our estimate is larger (more negative) in these cases.

We also show that the effect is larger (more negative) for more professionalized legislatures and for legislatures that pay higher salaries. Because the benefits of holding office are higher in these legislatures (they pay more, are more prestigious, and are full-time jobs), models of accountability would suggest that electoral incentives should be stronger in these cases. Again, that we find this theoretically predicted heterogeneity is reassuring.

\section{Do Termed-Out Legislators Run for Other Offices?}

The estimates above are likely a lower bound on the effects of the removal of electoral incentives because these term limits do not truly remove all electoral incentives. Some state legislators who are termed out go on to run for other offices, including the other chamber of their state legislature if allowed, and may consider these future campaigns when structuring their behavior in their final term. ${ }^{14}$ To the extent this behavior occurs, it makes the "treatment" of being term limited weaker because legislators who have committed to running for another office in short order still face meaningful incentives that could structure how they allocate their effort in their final term. This would make them similar to the control legislators, who also face electoral incentives, and would thereby attenuate the estimate to some degree. Consistent with this possibility, Table A.3 in the Appendix shows evidence that the effect of being term limited is larger (more negative) in California and Oklahoma. In these two states, term limits are cumulative, which means that once a legislator hits her binding term limit, she cannot run for either legislative chamber in the future. Even so, we continue to find a large and negative estimate for other term-

\footnotetext{
${ }^{14}$ Ban, Llaudet, and Snyder (2016) show that term-limited state legislators are more likely than other state legislators to run for the U.S. House. On the other hand, the baseline rate at which state legislators run for the House is only around 1\% (Hall 2018) and the part-time nature of many state legislatures suggests that many legislators go back to their day jobs when not holding political office.
}

limited states, probably because many termed-out legislators do not run for other offices and thus have weak electoral incentives in their final term.

\section{TERMED-OUT LEGISLATORS DO NOT SEEM TO SHIFT PLATFORMS}

In the final part of the paper, we evaluate whether being term limited leads legislators to systematically shift their ideological platforms. If electoral incentives encourage legislators to adopt more responsive ideological platforms-as posited by the "marginality hypothesis" (e.g., Fiorina 1973) and related accounts about "ideological shirking" (Bender and Lott 1996) then we might expect this pushes their platforms toward the center, on average; as a result, when electoral incentives are removed, we might expect to see Republicans move farther to the right, ideologically, and Democrats to move farther to the left.

On the other hand, if electoral incentives encourage legislators to pander to their bases (e.g., Canes-Wrone, Herron, and Shotts 2001), we might expect them to push their platforms to the extreme, in which case they might move back toward the middle when they no longer have to seek reelection.

Finally, if electoral incentives do not affect candidate positioning-either because election results are not sensitive to changes in candidate platforms or because candidates cannot or will not credibly change their platforms on the fly-then we might see no change in positions for termed-out legislators. ${ }^{15}$

Previous empirical literature has not evaluated this exact question and in general has come to mixed conclusions on the role of electoral incentives in ideological positioning. There is a very large body of research on the question of how legislators behave during "lameduck" sessions - for a review, see Bender and Lott (1996) - but it is mainly focused on party-level outcomes, and results on whether legislators "shirk" ideologically are very mixed. Empirical evaluations of the marginality hypothesis also come to mixed conclusions, though more recent research argues that electoral competition does encourage moderation Griffin (2006). By looking for individual-level shifts in ideological positioning in response to binding term limits, we can contribute to these literatures by providing evidence from an especially strong research design that varies the degree of electoral incentives at the level of the individual legislator.

We first use our design to evaluate whether termedout legislators systematically shift their ideological positions as measured using W-NOMINATE. Table 5 presents the results. In the first column, the outcome is the absolute value of W-NOMINATE. If legislators become more ideologically extreme when they are not

\footnotetext{
${ }^{15}$ This would be consistent with the findings in Titiunik (2016), where longer term lengths, which can be thought of as a way of diluting immediate electoral incentives, do not lead to greater ideological responsiveness.
} 
TABLE 5. Effect of Electoral Incentives on Legislator Voting Behavior

\begin{tabular}{|c|c|c|c|}
\hline & (1) & (2) & (3) \\
\hline & $\begin{array}{c}\text { Abs } \\
\text { WNOM }\end{array}$ & $\begin{array}{c}\text { WNOM } \\
\text { Dem }\end{array}$ & $\begin{array}{c}\text { WNOM } \\
\text { Rep }\end{array}$ \\
\hline Term limited & $\begin{array}{c}0.02 \\
(0.01)\end{array}$ & $\begin{array}{c}-0.00 \\
(0.01)\end{array}$ & $\begin{array}{c}-0.01 \\
(0.02)\end{array}$ \\
\hline$N$ & 4,356 & 2,192 & 2,143 \\
\hline Outcome mean & 0.63 & -0.62 & 0.52 \\
\hline Standard dev. & 0.23 & 0.33 & 0.38 \\
\hline Chamber-year FE & Yes & Yes & Yes \\
\hline Legislator FE & Yes & Yes & Yes \\
\hline
\end{tabular}

tempered by electoral incentives, one would expect a positive effect. The coefficient is positive, but it is only marginally statistically significant, and it is small in magnitude. In the next two columns, we split the sample into Republicans and Democrats and estimate the effects on their W-NOMINATE separately. These effects are very small in magnitude and statistically indistinguishable from zero.

While these results are suggestive, it is possible that W-NOMINATE is too crude of a measure to detect important individual-level shifts in ideological positioning. To evaluate potential ideological shifts another way, we use interest group scores of legislators' issuespecific voting records. For each legislator for whom we have a set of interest-group ratings, we reshape the data such that each row now corresponds to a legislator $i$ in chamber $c$ ranked by interest group $j$ in term $t$. We estimate the effects separately for each issue area and each party by running separate OLS regressions of the following form:

Interest Group Score $_{i j c t}=\beta$ Term Limited $i j c t+\gamma_{i j}+\theta_{j c t}+\varepsilon_{i j c t}$,

where Interest Group Score ijct $_{\text {is }}$ interest group j's score of legislator $i$ in chamber $c$ at time $t$, Term Limited Lict $_{\text {t }}$ indicates that legislator $i$ was term limited at time $t$ in chamber $c, \gamma_{i j}$ represents legislator-by-interest group fixed effects, $\theta_{j c t}$ represents interest group-by-chamber-by-year fixed effects, and $\varepsilon_{i j c t}$ is the error term. The coefficient of interest is $\beta$, and note that we estimate this coefficient separately for each category and party.

Figure 2 presents the results. Overall, the results are similar to the W-NOMINATE results. All estimates are small in magnitude-most point estimates are located between 0 and \pm 1 percentage point. Relative to the 0-100 scale, these effects are small and, statistically speaking, they are indistinguishable from zero. There does not seem to be a particular pattern across parties or interest-group categories. Overall, the findings do not suggest that legislators fundamentally change their ideological positions when they are termed out of office.

We should be cautious in interpreting the results because these analyses are only able to detect systematic deviations. If legislators systematically shift to the right and left, or to the middle, our design should detect this. On the other hand, if different legislators within the same party deviate in different directionsfor example, if legislators have heterogeneous personal ideological preferences and they deviate toward these personal preferences when electoral incentives are removed-our design will not detect this. Thus, the null results we find suggest that there are not systematic, predictable shifts in ideological platforms when electoral incentives are diminished, but they do not rule out other kinds of idiosyncratic shifts in positioning.

Nevertheless, in contrast with the marginality hypothesis and other accounts that link electoral incentives to increased ideological responsiveness, the results suggest the potentially limited power of elections to drive major changes in ideological positioning. These findings are in line with past research on the general rigidity of candidate platforms (Hall 2018; Lee, Moretti, and Butler 2004; Poole and Rosenthal 2000) and with research suggesting the limited link between candidate positions and electoral outcomes in state legislatures (Rogers 2017).

\section{CONCLUSION}

A main purpose of elections is to influence incumbents' behavior by forcing them to consider their prospects for reelection. How much elections succeed in influencing incumbent behavior is unclear, though. The bulk of democratically elected politicians in the world are legislators, who work together to set policy and have limited opportunities to differentiate themselves from their copartisans. The conventional wisdom in much of the literature on legislators and voter behavior is that 
FIGURE 2. Effect of Electoral Incentives on Interest Group Ratings

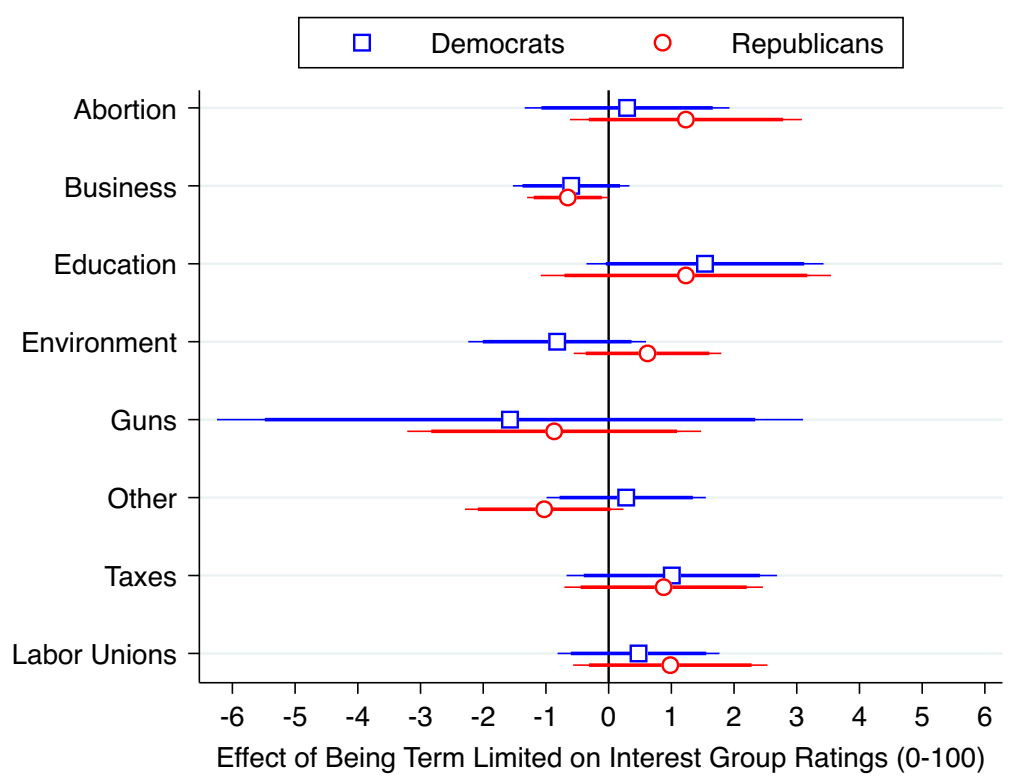

this collective behavior prevents voters from paying attention to the actions of individual legislators, in turn eroding the ability of electoral incentives to influence individual legislators' behavior.

Whether electoral incentives influence legislator behavior has been an elusive question to study because it is hard to obtain exogenous variation in electoral incentives. We have followed previous work on executive office accountability by taking advantage of term limits, which offer the chance to observe how incumbents behave in the absence of strong electoral incentives. We build on existing designs because the term limits in the legislatures we study are three terms or longer in length, allowing us to implement a stronger difference-in-differences design based on withinincumbent comparisons using within-state counterfactual trends.

Our evidence suggests that electoral incentives influence how legislators allocate their effort in important ways. Elections appear to induce incumbents to allocate their effort toward observable measures of productivity; once term-limited, we have shown, incumbent legislators sponsor fewer bills, provide less committee service, and are absent for more roll-call votes, on average.

On the other hand, electoral incentives do not appear to affect ideological positioning, to the extent we can study it. We find no evidence that incumbents become more extreme or more moderate in their final, termlimited term. This is consistent with theoretical work that postulates that candidates cannot commit to lesspreferred platforms and always implement their preferred policies (Alesina 1988; Besley and Coate 1997; Osborne and Slivinski 1996). It is also consistent with behavioral accounts that suggest that voters do not pay attention to candidate platforms and with evidence that the relationship between candidate moderation and election outcomes in state legislatures is muted (Rogers 2017).

While our focus in this study is not on evaluating the causal effects of term limits as a policy, our results are certainly relevant to the long-running debate over term limits. A major argument against legislative term limits is that they might lead to shirking by final-term incumbents who no longer need to seek reelection. While our results are consistent with that possibility, they do not establish that term limits cause shirking for two reasons. First, while we can confidently say that term-limited legislators allocate less effort toward the visible components of effort that we study-roll-call voting, bill sponsorship, and committee service-we do not know what else they might allocate efforts toward as a result. They could simply be spending more time in leisure, but they could also be spending more time serving their constituents in other ways. Second, our estimates are not sufficient to assess what happens to aggregate effort in the legislature in response to term limits. Term limits could lead individual incumbents to "shirk" in their final term while increasing the aggregate productivity of the legislature in other ways (e.g., by empowering new members of the legislature or by shifting more production to interest groups and lobbyists). For these reasons, we are cautious in applying our findings to the normative debate over term limits and see our analysis as primarily valuable for shedding light on the core function that elections play in altering the behavior of reelection-minded legislators.

The specific mechanisms by which elections influence how legislators allocate their effort is an important question that goes beyond the evidence we have presented in this paper. It is possible that there is a 
sufficient number of attentive voters even in state legislative elections so that incumbents must undertake visible activities these voters prefer. It is also possibleand, based on anecdotal evidence, likely - that parties and interest groups play large roles in shaping incumbent behavior in anticipation of electoral consequences. Whatever the mechanisms, our investigation reveals a striking ability for elections to influence how individual legislators allocate their effort, even in lowinformation settings like U.S. state legislatures, while seeming to have less influence on their ideological platforms.

\section{SUPPLEMENTARY MATERIALS}

To view supplementary material for this article, please visit http://doi.org/10.1017/S0003055421001064.

\section{DATA AVAILABILITY STATEMENT}

Research documentation and data that support the findings of this study are openly available at the American Political Science Review Dataverse: https://doi. org/10.7910/DVN/LHTRWM.

\section{ACKNOWLEDGMENTS}

For helpful discussion, the authors thank Avi Acharya, Scott Ashworth, Chris Berry, Adam Bonica, Filipe Campante, Ethan Bueno de Mesquita, Bruce Cain, Gary Cox, Jim Fearon, Anthony Fowler, Matt Gentzkow, Saad Gulzar, Alisa Hall, Will Howell, Navin Kartik, Steve Levitt, Julia Payson, Ken Scheve, Dan Smith, Dan Thompson, Stephane Wolton, and participants of the Stanford American Politics Workshop, the Political Economy workshop at the Harris School, the UChicago American Politics Workshop, the LSE PSPE seminar, Rochester's American Politics Workshop, Warwick's Political Economics seminar, the Washington PECO Conference, Yale's CSAP Annual American Politics Conference, and the Haas School of Business Political Economy Workshop. For excellent research assistance, we thank Rory Gates and Dylan Suffredini.

\section{CONFLICT OF INTEREST}

The authors declare no ethical issues or conflicts of interest in this research.

\section{ETHICAL STANDARDS}

The authors affirm this research did not involve human subjects.

\section{REFERENCES}

Alesina, Alberto. 1988. "Credibility and Policy Convergence in a Two-Party System with Rational Voters." American Economic Review 78 (4): 796-805.

Alt, James, Ethan Bueno de Mesquita, and Shanna Rose. 2011. "Disentangling Accountability and Competence in Elections: Evidence from U.S. Term Limits." Journal of Politics 73 (1): 17186.

Ansolabehere, Stephen, James M. Snyder, Jr. and Charles Stewart, III. 2001. "Candidate Positioning in US House Elections." American Journal of Political Science 45 (1): 136-59.

Ashworth, Scott. 2005. "Reputational Dynamics and Political Careers." Journal of Law, Economics, and Organization 21 (2): 441-66.

Ashworth, Scott. 2012. "Electoral Accountability: Recent Theoretical and Empirical Work." Annual Review of Political Science 15: 183-201.

Ban, Pamela, Elena Llaudet, and James M. Snyder, Jr. 2016. "Challenger Quality and the Incumbency Advantage." Legislative Studies Quarterly 41 (1): 153-79.

Banks, Jeffrey S., and Rangarajan K. Sundaram. 1998. "Optimal Retention in Agency Problems." Journal of Economic Theory 82 (2): 293-323.

Barber, Michael. 2015. "Ideological Donors, Contribution Limits, and the Polarization of American Legislatures." Journal of Politics 78 (1): 296-310.

Barro, Robert J. 1973. "The Control of Politicians: An Economic Model." Public Choice 14 (1): 19-42.

Bender, Bruce, and John R. Lott. 1996. "Legislator Voting and Shirking: A Critical Review of the Literature." Public Choice 87 (1-2): 67-100.

Besley, Timothy. 2006. Principled Agents? The Political Economy of Good Government. Oxford: Oxford University Press.

Besley, Timothy, and Anne Case. 1995. "Does Electoral Accountability Affect Economic Policy Choices? Evidence from Gubernatorial Term Limits." The Quarterly Journal of Economics 110 (3): 769-98.

Besley, Timothy, and Stephen Coate. 1997. "An Economic Model of Representative Democracy.” The Quarterly Journal of Economics 112 (1): 85-114.

Brown, Adam R., and Jay Goodliffe. 2017. "Why Do Legislators Skip Votes? Position Taking versus Policy Influence.” Political Behavior 39 (2): 425-55.

Butler, Daniel M., and David E. Broockman. 2011. "Do Politicians Racially Discriminate against Constituents? A Field Experiment on State Legislators." American Journal of Political Science 55 (3): 463-77.

Cain, Bruce E., and Thad Kousser. 2004. Adapting to Term Limits: Recent Experiences and New Directions. San Francisco: Public Policy Institute of California.

Campbell, Angus, Philip E. Converse, Warren E. Miller, and Donald E. Stokes. 1960. The American Voter. Chicago: University of Chicago Press.

Canes-Wrone, Brandice, David W. Brady, and John F. Cogan. 2002. "Out of Step, Out of Office: Electoral Accountability and House Members' Voting." American Political Science Review 96 (1): 127-40.

Canes-Wrone, Brandice, Michael C. Herron, and Kenneth W. Shotts. 2001. "Leadership and Pandering: A Theory of Executive Policymaking." American Journal of Political Science 45 (3): 532-50.

Carroll, Royce, Jeffrey B. Lewis, James Lo, Keith T. Poole, and Howard Rosenthal. 2009. "Comparing NOMINATE and IDEAL: Points of Difference and Monte Carlo Tests." Legislative Studies Quarterly 34 (4): 555-91.

Caughey, Devin, and Christopher Warshaw. 2020. "Electoral Accountability for Ideological Extremism in American Elections." Working Paper. http://www.nyu.edu/projects/politicsdatalab/ Warshaw_Accountability_NYU.pdf.

Dal Bó, Ernesto, and Martín A. Rossi. 2011. "Term Length and the Effort of Politicians.” The Review of Economic Studies 78 (4): 1237-63.

De Benedictis-Kessner, Justin, and Christopher Warshaw. 2020. "Accountability for the Local Economy at All Levels of 
Government in United States Elections." American Political Science Review 114 (3): 660-76.

Downs, Anthony. 1957. An Economic Theory of Democracy. New York: Harper and Row.

Fearon, James D. 1999. "Electoral Accountability and the Control of Politicians: Selecting Good Types versus Sanctioning Poor Performance." In Democracy, Accountability, and Representation, eds. Bernard Mann, Adam Przeworski, and Susan C. Stokes, 55-97. Cambridge: Cambridge University Press.

Ferraz, Claudio, and Frederico Finan. 2011. "Electoral Accountability and Corruption: Evidence from the Audits of Local Governments." American Economic Review 101 (4): 1274-311.

Fiorina, Morris P. 1973. "Electoral Margins, Constituency Influence, and Policy Moderation: A Critical Assessment." American Politics Quarterly 1 (4): 479-98.

Fouirnaies, Alexander. 2018. "When Are Agenda Setters Valuable?" American Journal of Political Science 62 (1): 176-91.

Fouirnaies, Alexander, and Andrew B. Hall. 2018. "How Do Interest Groups Seek Access to Committees?" American Journal of Political Science 62 (1): 132-47.

Fouirnaies, Alexander, and Andrew B. Hall. 2021. "Replication Data for: How Do Electoral Incentives Affect Legislator Behavior? Evidence from U.S. State Legislatures." Harvard Dataverse Dataset. https://doi.org/10.7910/DVN/LHTRWM.

Gilligan, Thomas W., and Keith Krehbiel. 1987. "Collective Decisionmaking and Standing Committees: An Informational Rationale for Restrictive Amendment Procedures.” Journal of Law, Economics and Organization 3 (2): 287-335.

Griffin, John D. 2006. "Electoral Competition and Democratic Responsiveness: A Defense of the Marginality Hypothesis." Journal of Politics 68 (4): 911-21.

Grumbach, Jacob M., and Alexander Sahn. 2020. "Race and Representation in Campaign Finance." American Political Science Review 114 (1): 206-21.

Hall, Andrew B. 2018. Who Wants to Run? How the Devaluing of Office Drives Polarization. Chicago: University of Chicago Press.

Harvey, Anna, and Taylor Mattia. Forthcoming. "Does Money Have a Conservative Bias? Estimating the Causal Impact of Citizens United on State Legislative Preferences." Public Choice.

Huber, Gregory A., and Sanford C. Gordon. 2004. "Accountability and Coercion: Is Justice Blind When It Runs for Office?" American Journal of Political Science 48 (2): 247-63.

Kartik, Navin, and Richard Van Weelden. 2019. "Reputation Effects and Incumbency (Dis)Advantage." Quarterly Journal of Political Science 14 (2): 131-57.

Kathlene, Lyn. 1994. "Power and Influence in State Legislative Policymaking: The Interaction of Gender and Position in Committee Hearing Debates." American Political Science Review 88 (3): 560-76.

Klarner, Carl, William Berry, Thomas Carsey, Malcolm Jewell, Richard Niemi, Lynda Powell, and James Snyder. 2013. "State Legislative Election Returns (1967-2010).” Inter-University Consortium for Political and Social Research (ICPSR).

Kousser, Thad. 2005. Term Limits and the Dismantling of State Legislative Professionalism. Cambridge: Cambridge University Press.

Kroeger, Mary A. 2017. "How Groups Write the Law: An Empirical Analysis of Group Influence in American State Legislatures." $\mathrm{PhD}$ diss. Princeton Univerity. https://dataspace.princeton.edu/ handle/88435/dsp018p58pg59d.

Lee, David S., Enrico Moretti, and Matthew J. Butler. 2004. "Do Voters Affect or Elect Policies? Evidence from the US House." The Quarterly Journal of Economics 119 (3): 807-59.

Lim, Claire S. H., James M. Snyder, Jr. and David Strömberg. 2015. "The Judge, the Politician, and the Press: Newspaper Coverage and Criminal Sentencing across Electoral Systems." American Economic Journal: Applied Economics 7 (4): 103-35.

List, John A., and Daniel M. Sturm. 2006. "How Elections Matter: Theory and Evidence from Environmental Policy." The Quarterly Journal of Economics 121 (4): 1249-81.

Mayhew, David R. 1974. Congress: The Electoral Connection, Vol. 26. New Haven, CT: Yale University Press.

Moncrief, Gary, Lynda W. Powell, and Tim Storey. 2007. "Composition of Legislatures." In Institutional Change in American Politics: The Case of Term Limits, eds. Karl T. Kurtz, Bruce Cain, and Richard G. Niemi, 22-37. Ann Arbor: University of Michigan Press.

Mooney, Christopher Z. 2009. "Term Limits as a Boon to Legislative Scholarship: A Review." State Politics \& Policy Quarterly 9 (2): 204-28.

Motolinia, Lucia. 2021. "Electoral Accountability and Particularistic Legislation: Evidence from an Electoral Reform in Mexico." American Political Science Review 115 (1): 97-113.

Olson, Michael P., and Jon C. Rogowski. 2020. "Legislative Term Limits and Polarization." Journal of Politics 82 (2): 572-86.

Osborne, Martin J., and Al Slivinski. 1996. "A Model of Political Competition with Citizen-Candidates." The Quarterly Journal of Economics 111 (1): 65-96.

Poole, Keith T., and Howard Rosenthal. 1985. "A Spatial Model for Legislative Roll Call Analysis.” American Journal of Political Science 29 (2): 357-84.

Poole, Keith T., and Howard Rosenthal. 2000. Congress: A PoliticalEconomic History of Roll Call Voting. New York: Oxford University Press.

Rogers, Steven. 2016. "National Forces in State Legislative Elections." Annals of the American Academy of Political and Social Science 667 (1): 207-25.

Rogers, Steven. 2017. "Electoral Accountability for State Legislative Roll Calls and Ideological Representation." American Political Science Review 111 (3): 555-71.

Rothenberg, Lawrence S., and Mitchell S. Sanders. 2000. "Severing the Electoral Connection: Shirking in the Contemporary Congress." American Journal of Political Science 44 (2): 316-25.

Sanbonmatsu, Kira. 2002. "Political Parties and the Recruitment of Women to State Legislatures." Journal of Politics 64 (3): 791-809.

Schiller, Wendy J. 1995. "Senators as Political Entrepreneurs: Using Bill Sponsorship to Shape Legislative Agendas." American Journal of Political Science 39 (1): 186-203.

Shepsle, Kenneth A. 1972. "The Strategy of Ambiguity: Uncertainty and Electoral Competition." American Political Science Review 66 (2): 555-68.

Shepsle, Kenneth A. 1978. The Giant Jigsaw Puzzle: Democratic Committee Assignments in the Modern House. Chicago: University of Chicago Press.

Shor, Boris, and Nolan McCarty. 2011. "The Ideological Mapping of American Legislatures." American Political Science Review 105 (3): 530-51.

Sieg, Holger, and Chamna Yoon. 2017. "Estimating Dynamic Games of Electoral Competition to Evaluate Term Limits in U.S. Gubernatorial Elections." American Economic Review 107 (7): 1824-57.

Spenkuch, Jörg L., B. Pablo Montagnes, and Daniel B. Magleby. 2018. "Backward Induction in the Wild? Evidence from Sequential Voting in the US Senate." American Economic Review 108 (7): 1971-2013.

Titiunik, Rocío. 2016. "Drawing Your Senator from a Jar: Term Length and Legislative Behavior." Political Science Research and Methods 4 (2): 293-316. 